\title{
Urolithin A attenuates memory impairment and neuroinflammation in APP/PS1 mice
}

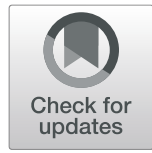

\author{
Zhuo Gong ${ }^{1 \dagger}$, Jingyi Huang ${ }^{1 \dagger}$, Biao $\mathrm{Xu}^{1 \dagger}$, Zhenri Ou${ }^{1 \dagger}$, Le Zhang ${ }^{1}$, Xiaohong Lin ${ }^{1}$, Xiujuan Ye ${ }^{1}$, Xuejian Kong ${ }^{2}$, \\ Dahong Long ${ }^{1}$, Xiangdong Sun ${ }^{1}$, Xiaosong He${ }^{1}$, Liping Xu', Qingqing $\mathrm{Li}^{1}$ and Aiguo Xuan ${ }^{1 *}$
}

\begin{abstract}
Background: Alzheimer's disease (AD) is a progressive neurodegenerative disorder characterized by an abnormal accumulation of amyloid- $\beta$ (A $\beta$ ) plaques, neuroinflammation, and impaired neurogenesis. Urolithin $A(U A)$, a gutmicrobial metabolite of ellagic acid, has been reported to exert anti-inflammatory effects in the brain. However, it is unknown whether UA exerts its properties of anti-inflammation and neuronal protection in the APPswe/PS1 $\triangle E 9$ (APP/PS1) mouse model of AD.
\end{abstract}

Methods: Morris water maze was used to detect the cognitive function. Terminal deoxynucleotidyl transferase-mediated dUTP nick end labeling (TUNEL) assay was performed to detect neuronal apoptosis. Immunohistochemistry analyzed the response of glia, $A \beta$ deposition, and neurogenesis. The expression of inflammatory mediators were measured by enzymelinked immunosorbent assay (ELISA) and quantitative real-time polymerase chain reaction (qRT-PCR). The modulating effects of UA on cell signaling pathways were assayed by Western blotting.

Results: We demonstrated that UA ameliorated cognitive impairment, prevented neuronal apoptosis, and enhanced neurogenesis in APP/PS1 mice. Furthermore, UA attenuated A $\beta$ deposition and peri-plaque microgliosis and astrocytosis in the cortex and hippocampus. We also found that UA affected critical cell signaling pathways, specifically by enhancing cerebral AMPK activation, decreasing the activation of P65NF-KB and P38MAPK, and suppressing Bace1 and APP degradation.

Conclusions: Our results indicated that UA imparted cognitive protection by protecting neurons from death and triggering neurogenesis via anti-inflammatory signaling in APP/PS1 mice, suggesting that UA might be a promising therapeutic drug to treat AD.

Keywords: Alzheimer's disease, Urolithin A, Neuroinflammation, Memory impairment, Neurogenesis

\section{Introduction}

Alzheimer's disease (AD) is a multifaceted neurodegenerative disorder that causes cognitive deterioration and has no effective cure. The histopathological hallmarks of $\mathrm{AD}$ are the increase in neuronal amyloid- $\beta(\mathrm{A} \beta)$ plaque formation, hyperphosphorylated tau protein, neuroinflammation, and neuronal loss [1]. A $\beta$ accumulation has been shown to recruit activated glia [2]. Indeed, reactive

\footnotetext{
* Correspondence: xag2005@163.com

Zhuo Gong, Jingyi Huang, Biao Xu, and Zhenri Ou contributed equally to this article.

${ }^{1}$ Institute of Neuroscience and Department of Neurology of the Second Affiliated Hospital of Guangzhou Medical University, Key Laboratory of Neurogenetics and Channelopathies of Guangdong Province and the Ministry of Education of China, Guangzhou 510260, China

Full list of author information is available at the end of the article
}

gliosis is increasingly regarded as an important player in the neuropathological processes of AD. Activated microglia and astrocytes have been reported to produce a wide range of proinflammatory factors such as IL-1 $\beta$ and IL-6, which increased amyloid precursor protein (APP) expression and $\mathrm{A} \beta$ deposition in models of $\mathrm{AD}[3,4]$. Conversely, activated glia also promoted the phagocytosis of the $A \beta$ oligomer [5]. These findings show that activated glia have dual and opposing roles with respect to neuroinflammation in $A \beta$ pathology. Numerous epidemiological reports supported the finding that anti-inflammatory therapy can reduce the risk for AD by more than $50 \%[6,7]$. Thus, anti-inflammatory therapy has been proposed as a potential therapeutic strategy for AD.

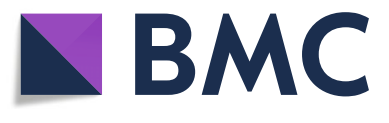

(c) The Author(s). 2019 Open Access This article is distributed under the terms of the Creative Commons Attribution 4.0 International License (http://creativecommons.org/licenses/by/4.0/), which permits unrestricted use, distribution, and reproduction in any medium, provided you give appropriate credit to the original author(s) and the source, provide a link to the Creative Commons license, and indicate if changes were made. The Creative Commons Public Domain Dedication waiver (http://creativecommons.org/publicdomain/zero/1.0/) applies to the data made available in this article, unless otherwise stated. 
Ellagic acid (EA) is a hydrolyzed form of ellagitannins (ETs), which are abundant in pomegranate, berries, and nuts. Complex dietary EA and ETs are poorly absorbed in humans, but they get further metabolized by gut microflora to yield a series of urolithins [8]. Among the urolithin species, urolithin A (UA) is the major metabolite observed in humans [9]. Several studies have demonstrated that UA had anti-inflammatory and antioxidant properties in vitro and in vivo [10-14]. However, it is unknown whether UA improves cognitive function and attenuates neuroinflammation in the APPswe/PS1 $\triangle \mathrm{E} 9$ (APP/PS1) transgenic mouse model of AD. Therefore, the aim of this study was to determine if UA can rescue cognitive impairment in APP/PS1 mice and to elucidate the underlying cellular and molecular mechanisms of its effects.

\section{Methods and materials}

\section{Animals and drug treatment}

Female APP/PS1 transgenic mice were purchased from The Jackson Laboratory (Strain name: B6C3-Tg (APPswe, PS1dE9) 85Dbo/J; No. 004462). Age- and gender-matched wild-type (WT) littermates were used as controls. The mice were allowed to adapt to the laboratory environment before testing. The experiments were carried out in compliance with The Guidelines for Animal Care and Use of China, and the experimental protocols were approved by the animal ethics committee of Guangzhou Medical University.

Mice (28 weeks old) were orally administered $300 \mathrm{mg} /$ kg UA (Standard, China) dissolved in 0.5\% carboxymethylcellulose at the same time each day for 14 days. Control mice (APP/PS1 transgenic mice and wild-type mice) were orally administered the same quantity of $0.5 \%$ carboxymethylcellulose (vehicle).

\section{Morris water maze}

After UA treatment, the spatial learning and memory of mice were assessed by the Morris water maze. Briefly, the maze consisted of a stainless steel pool $(120 \mathrm{~cm}$ in diameter and $50 \mathrm{~cm}$ in height) with a submerged escape-platform (10 $\mathrm{cm}$ in diameter) placed $1 \mathrm{~cm}$ below the water surface. The water temperature was maintained at $24 \pm 1{ }^{\circ} \mathrm{C}$. The spatial learning task consisted of four consecutive days of testing with four trials per day. In each trial, the time required to find the hidden platform was recorded as the escape latency. The mice were given a maximum of $60 \mathrm{~s}$ to find the hidden platform. If a mouse failed to locate the platform within $60 \mathrm{~s}$, the session was terminated, a maximum escape-latency score of $60 \mathrm{~s}$ was assigned, and the mouse was manually guided to the hidden platform (10 s). To test spatial memory, a single probe trial was conducted $24 \mathrm{~h}$ after the last trial of the fourth day. The submerged platform was removed and the mice were placed into the pool from the quadrant opposite to the quadrant where the platform used to be (target quadrant). The mice were allowed to freely swim for $60 \mathrm{~s}$. The time spent in the target quadrant and numbers of crossings through this quadrant were recorded. Swimming speed was also recorded. All of the behavioral parameters of the mice were tracked, recorded, and analyzed using SMART 3.0 software (Harvard Apparatus).

\section{Immunohistochemistry and immunofluorescence}

After the behavioral tests, the mice were anesthetized and transcardially perfused with phosphate-buffered saline (PBS; Boster, China). The brains were removed and post-fixed with paraformaldehyde overnight. They were then incubated in 30\% sucrose in PBS for cryoprotection, and $30-\mu \mathrm{m}$ serial sections were cut using a cryostat. Next, the sections were incubated with $0.3 \% \mathrm{H}_{2} \mathrm{O}_{2}$ in methanol for $10 \mathrm{~min}$, followed by a blocking solution of $10 \%$ normal goat serum in PBS for 20 min. For immunohistochemistry, the sections were incubated with primary antibody (anti-NeuN (1:200, 24307, CST, USA), anti-A 340 (1:500, 44047, NOVUS, USA), anti-A $\beta 42$ (1:200, 14974, CST, USA), and anti-Iba-1 (1:500, 100-1028, NOVUS, USA) at $4{ }^{\circ} \mathrm{C}$ overnight and then $37{ }^{\circ} \mathrm{C}$ for $30 \mathrm{~min}$. After being washed in PBS the following day, the sections were incubated with biotinylated anti-mouse or anti-rabbit secondary antibodies (Boster, China) in PBS for $30 \mathrm{~min}$ at $37^{\circ} \mathrm{C}$. They were then incubated with avidin-biotin peroxidase solution (SABC kit, Boster, China) and colorized with a 3,3'-diaminobenzidine (DAB) kit (Boster, China). For immunofluorescence, the sections were incubated with anti-DCX (Doublecortin, 1:200, 4604, CST, USA), anti-A $\beta$ (anti-A $\beta, 1: 200,8243$, CST, USA), and anti-GFAP (Abcam, 1:800, 4674, Abcam, USA) in the blocking solution at $4{ }^{\circ} \mathrm{C}$ overnight. The following day, the sections were washed three times in PBS and incubated with Alexa 488- or Alexa 594-conjugated IgG secondary antibodies (Invitrogen, CA, USA) at room temperature for $2 \mathrm{~h}$. Nuclei were counterstained by incubation in $1 \mu \mathrm{g} / \mathrm{ml} \mathrm{4',6-diamidino-2-phenylindole} \mathrm{(DAPI)}$ (Solarbio, China) for 15 min followed by exhaustive washing in distilled water. Coverslips were mounted in Gel Mount (VECTASHIELD, CA, USA), and the sections were inspected under a scanning confocal microscope (Leica, Germany).

Quantitative analysis of immuno-positive cells present in the sections was carried out under microscopic magnifications (Olympus, Japan) and was assessed from six random fields of view in each section (three sections per animal) using CellF software (Olympus). In each animal, one coronal section was taken from the anterior ( $-1.22 \mathrm{~mm}$ from bregma), one from the middle $(-1.70 \mathrm{~mm}$ from bregma), and one from the posterior hippocampus 
(-2.80 $\mathrm{mm}$ from bregma). The data are presented as the mean number of positive cells $/ \mathrm{mm}^{2}$ in the tiled images. For the quantification of GFAP-positive cells, cell identity was ascertained by DAPI localization. Double-labeled cells positive for GFAP and DAPI were counted per $\mathrm{mm}^{2}$ from six random fields of view in each section under a fluorescence microscope (Olympus, Japan). The A $\beta$ staining area (\%) was calculated relative to the total area of the analyzed region (\% area = plaque area/total area selected $\times 100$ ). All of the cell counting was performed in a blinded fashion.

\section{Terminal deoxynucleotidyl transferase dUTP nick end labeling detection}

The in situ terminal deoxynucleotidyl transferase dUTP nick end labeling (TUNEL) technique was performed according to the manufacturer's instructions for the apoptosis kit (Roche, Basel, Switzerland). Briefly, sections were immersed in $0.3 \% \mathrm{H}_{2} \mathrm{O}_{2}$ and then incubated for $120 \mathrm{~min}$ at $37^{\circ} \mathrm{C}$ with TUNEL-labeling buffer, followed by $30 \mathrm{~min}$ at $37{ }^{\circ} \mathrm{C}$ in the avidin-biotin peroxidase solution. Next, the sections were rinsed in PBS and incubated for $10 \mathrm{~min}$ with $\mathrm{DAB}$ substrate solution. Three coronal sections were used for analysis, where the number of TUNEL-positive cells was manually counted in the cortex and hippocampus of the ipsilateral hemisphere. Imaging and cell counting were conducted using an Olympus light microscope (Olympus, Japan), and the resulting data are presented as the number of TUNELpositive cells $/ \mathrm{mm}^{2}$.

\section{5-Bromo-2'-deoxyuridine labeling}

5-Bromo-2'-deoxyuridine (BrdU) (Sigma-Aldrich) was administered intraperitoneally as a single injection of $100 \mathrm{mg} / \mathrm{kg}$ per day for 1 week preceding the behavioral tests, and a remainder of $100 \mathrm{mg} / \mathrm{kg} 24 \mathrm{~h}$ immediately before the animals were killed. For BrdU labeling, the non-specific binding sites were blocked by incubation in a blocking serum (bovine serum albumin 3\%, Triton $\mathrm{X}-100 \quad 0.3 \%$ ) for $10 \mathrm{~min}$ and then incubated with anti-BrdU (Abcam) at $4{ }^{\circ} \mathrm{C}$ overnight. The following day, brain sections were incubated for $1 \mathrm{~h}$ at room temperature with secondary antibody (FITC; Abcam) dissolved in the blocking serum. Nuclei were counterstained with DAPI. Coverslips were mounted in Gel Mount (Vectashield, CA), and the sections were inspected under a scanning confocal microscope (Leica, Germany).

\section{ELISA}

Brain tissue was homogenized in RIPA buffer, sonicated briefly, and centrifuged. The supernatants were collected and quantified for soluble $A \beta 40$ (DAB140B), A $\beta 42$ (DAB142), IL-1 $\beta$ (DY401-05), IL-6 (DY406-05), and
TNF- $\alpha$ (DY410-05) using enzyme-linked immunosorbent assay (ELISA) kits (R\&D Systems, USA) according to the manufacturer's instructions.

\section{Real-time reverse transcription-PCR}

Total RNA from hippocampal and cortical tissue was extracted using TriZol reagent (Invitrogen, USA). Reverse transcription was performed with an ExScript RT Reagent Kit (Takara Bio Inc., China). Real-time PCR analysis was conducted using SYBR Premix Ex Taq (Takara Bio Inc., China). The PCR primer sequences were as follows: IL-1 $\beta$ (Accession number: NM_008361): 5'-AATG CCACCTTTTGACAGTGAT-3' (sense) and 5' ${ }^{\prime}$-TGCT GCGGGATTTGAAGCTG-3' (antisense); IL-6 (Accession number: NM_031168): 5'-AGGATACCACTCCC AACAGACC-3' (sense) and 5'-AAGTGCATCATCGT TCATACA-3' (antisense); TNF- $\alpha$ (Accession number: NM_013693): 5' -CACGTCGTAGCAAACCACC-3' (sense) and 5'-TGAGATCCATGCCGTTGGC-3' (antisense); $\beta$-actin (Accession number: NM_007393): 5'-GCTGTGCTATGTTG CTCTAG-3' (sense) and 5'-CGCTCGTTGCCAATAGTG-3' (antisense).

The PCR parameters included an initial denaturation at $95{ }^{\circ} \mathrm{C}$ for $30 \mathrm{~s}$, followed by 39 cycles of $95{ }^{\circ} \mathrm{C}$ for $5 \mathrm{~s}$ and $60{ }^{\circ} \mathrm{C}$ for $1 \mathrm{~min}$. The relative gene expression was normalized to the mean expression level of $\beta$-actin.

\section{Western blotting}

The expression levels of p-AMPK, p-P65NF-kB, p-P38MAPK, Bace1, and APP were analyzed by Western blotting. The protein samples were heated at $100{ }^{\circ} \mathrm{C}$ for 5 min with a loading buffer containing $0.125 \mathrm{M}$ Tris- $\mathrm{HCl}$ (pH 6.8), 20\% glycerol, 4\% SDS, $10 \%$ $\beta$-mercaptoethanol, and $0.002 \%$ bromophenol blue. The samples were then separated by sodium dodecyl sulfate-polyacrylamide gel electrophoresis (SDS-PAGE) and transferred onto polyvinylidene (PVDF) membranes. The membranes were incubated with $3 \%$ bovine serum albumin (BSA) in Tris-buffered saline with Tween (TBST) $(10 \mathrm{mmol} / \mathrm{L}$ Tris at $\mathrm{pH} 7.5,150 \mathrm{mmol} / \mathrm{L} \mathrm{NaCl}$, $0.05 \%$ Tween-20) and probed with corresponding primary antibodies (anti-p-AMPK, anti-p-P38MAPK, antip-P65NF-kB, anti-BACE1, and anti-APP; Cell Signaling Technology, Boston, USA) at $4{ }^{\circ} \mathrm{C}$ overnight. After incubation with horseradish peroxidase-coupled secondary antibodies for $2 \mathrm{~h}$ at room temperature, the protein bands were quantified by densitometry (Syngene, UK).

\section{Statistical analysis}

All of the values are expressed as the mean \pm standard error of the mean (SEM). For the Morris water maze experiments, the escape latency during the spatial learning tests was determined by a two-way repeated-measures analysis of variance (ANOVA) with Student-Newman-Keuls 
post-hoc tests. All of the other experiments were analyzed using one-way ANOVA followed by Bonferroni's post-hoc test. $P<0.05$ was considered significant.

\section{Results}

UA ameliorates learning and memory deficits in APP/PS1 mice

To investigate the potential therapeutic benefit of UA for the cognitive function of APP/PS1 mice, we conducted the Morris water maze to assess spatial learning and memory ability. We found that APP/PS1 mice spent more time locating the platform (escape latency) compared with wild-type (WT) mice, indicating a significant cognitive decline in terms of spatial learning. In addition, there was a significant difference in escape latency between UA-treated and vehicle-treated APP/PS1 mice, implying that cognitive function in terms of spatial memory was significantly improved by UA treatment (Fig. 1a). Swimming velocity remained stable among the three groups, suggesting that UA treatment did not influence the locomotor activity of mice (Fig. 1b). These findings showed that UA attenuated spatial learning deficits in APP/PS1 mice.

To test the effect of UA on spatial memory consolidation, probe trials were performed to assess the maintenance of spatial memory. Compared with WT mice, APP/ PS1 mice took longer to reach the location of the missing platform and crossed the target quadrant less often (Fig. 1c-e). However, UA-treated APP/PS1 mice showed significantly more time spent in the target quadrant and increased crossovers compared with vehicle-treated APP/PS1 mice (Fig. 1c-e). These results indicated that UA ameliorated the spatial memory of APP/PS1 mice.

\section{UA prevents cell death in APP/PS1 mice}

Neuronal degeneration and loss are regarded as the main contributors to the cognitive decline in $\mathrm{AD}$ patients [15] and APP/PS1 mice [16]. To assess whether
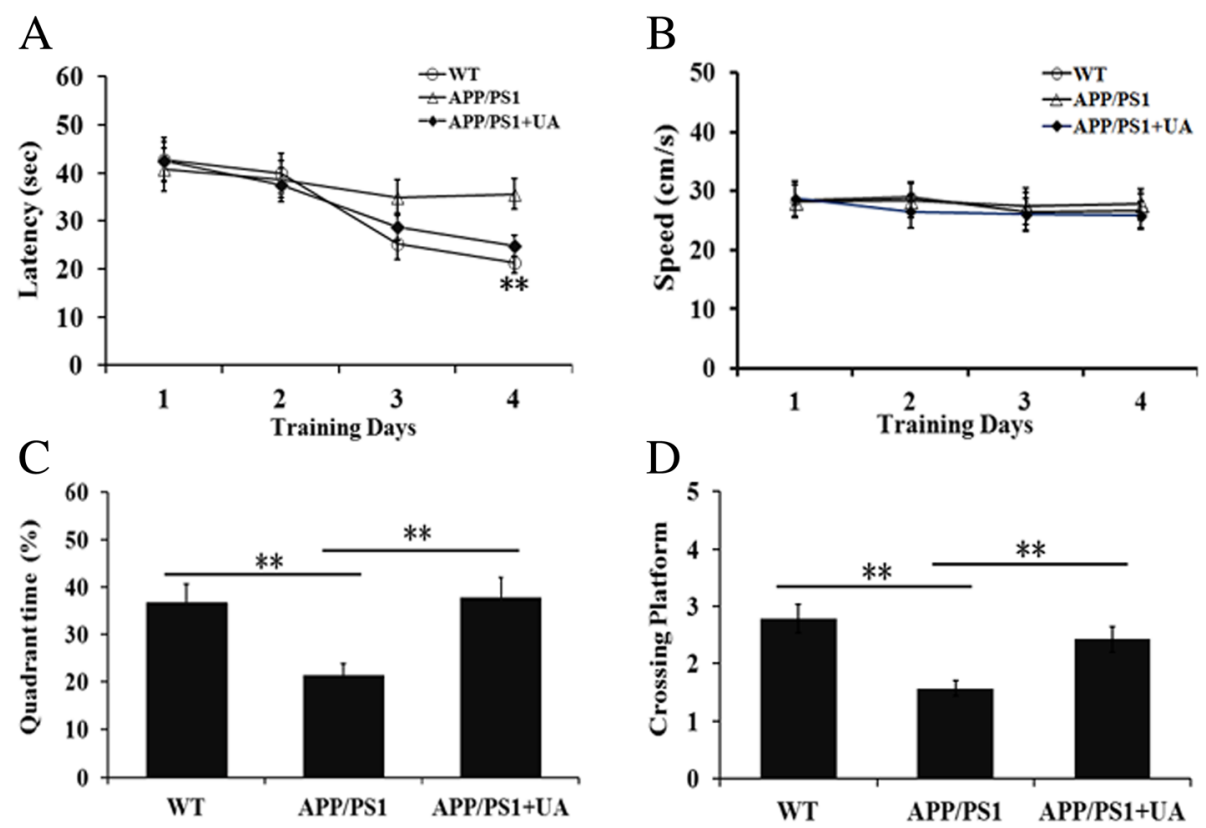

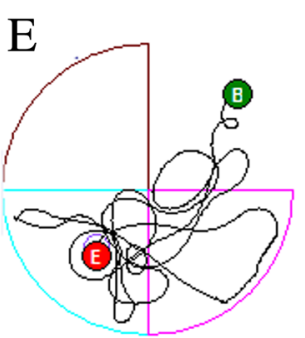

WT

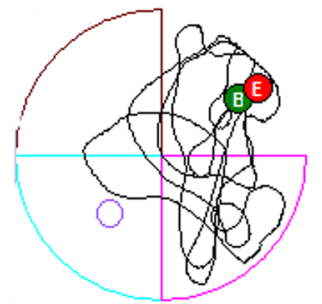

APP/PS1

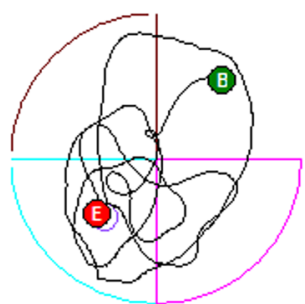

APP/PS1+UA

Fig. $1 \cup A$ counteracted cognitive decline in APP/PS1mice. a The escape latency in the spatial learning test. b The average swimming speed among all the groups. c The percentage of time spent in the target quadrant in the probe test. $\mathbf{d}$ The number of crossings through the target quadrant (where the platform was previously located) in the probe test. e Representative path tracings in each quadrant during the probe trial. All data are presented as the mean \pm SEM, $n=8-10$ mice per group. ${ }^{* *} P<0.01$; WT wild-type, UA urolithin A 
UA can attenuate cell death, we measured the change in the number of NeuN-positive $\left(\mathrm{NeuN}^{+}\right)$cells in the hippocampus. Our data showed that UA treatment prevented the loss of $\mathrm{NeuN}^{+}$immunoreactivity in the CA1 region of hippocampus of APP/PS1 mice (Fig. 2a, b). Results from the terminal deoxynucleotidyl transferase dUTP nick end labeling (TUNEL) assay further confirmed that UA significantly reduced cellular apoptosis in the cortex and hippocampal CA1 of APP/PS1 mice (Fig. 2c-h). These findings indicated that UA prevented cell death in the cortex and hippocampus of APP/PS1 mice.

UA enhances hippocampal neurogenesis in APP/PS1 mice Hippocampal neurogenesis plays an important role in hippocampal-dependent learning and memory [17]. To determine whether UA increases hippocampal neurogenesis, we performed bromodeoxyuridine (BrdU) and doublecortin (DCX) staining. Our results showed that significantly more $\mathrm{BrdU}$-positive $\left(\mathrm{BrdU}^{+}\right)$cells were seen in the UA-treated $\mathrm{AD}$ mice than in the vehicle-treated AD mice (Fig. 3a, c). In addition, compared with WT littermates, there were significantly fewer DCX-positive $\left(\mathrm{DCX}^{+}\right)$cells in the dentate gyri of vehicle-treated $\mathrm{AD}$ mice and significantly more in the dentate gyri of UA-treated AD mice (Fig. 3b, d). These results demonstrated that the diminished capacity for neurogenesis in
APP/PS1 mice was at least partially restored by UA treatment.

UA alleviates plaque burden and A $\beta$ levels in APP/PS1 mice To explore the effect of UA on the levels of $A \beta$ plaque deposits, immunohistochemistry with antibodies specific to $A \beta 40$ and $A \beta 42$ was performed on fixed brain tissue. The mean area covered by $A \beta 40$-positive and $A \beta 42$ positive plaques was markedly higher in the cortex and hippocampus of APP/PS1 mice compared with WT mice (Fig. 4a-d). However, UA treatment significantly decreased the mean area containing A $\beta$ plaques in APP/ PS1 mice (Fig. 4a-d). In addition, we also quantified the density of $A \beta 40$ - and $A \beta 42$-positive plaques in the cortex and hippocampus. Our results demonstrated that UA significantly reduced the plaque number $/ \mathrm{mm}^{2}$ of $A \beta 40$-positive and A 342 -positive plaques compared with APP/PS1 mice (Fig. 4a, b, e, f), suggesting an inhibitory effect of UA on $A \beta$ deposition.

Next, we performed an enzyme-linked immunosorbent assay (ELISA) to quantify $A \beta$ levels in the cortex and hippocampus of the AD mice. Our results showed that soluble $A \beta 40$ and $A \beta 42$ levels were high in APP/PS1 mice (Fig. 4g, h), but UA treatment significantly reduced the levels of soluble $A \beta 40$ and $A \beta 42$ in the cortex and hippocampus compared with the APP/PS1 group

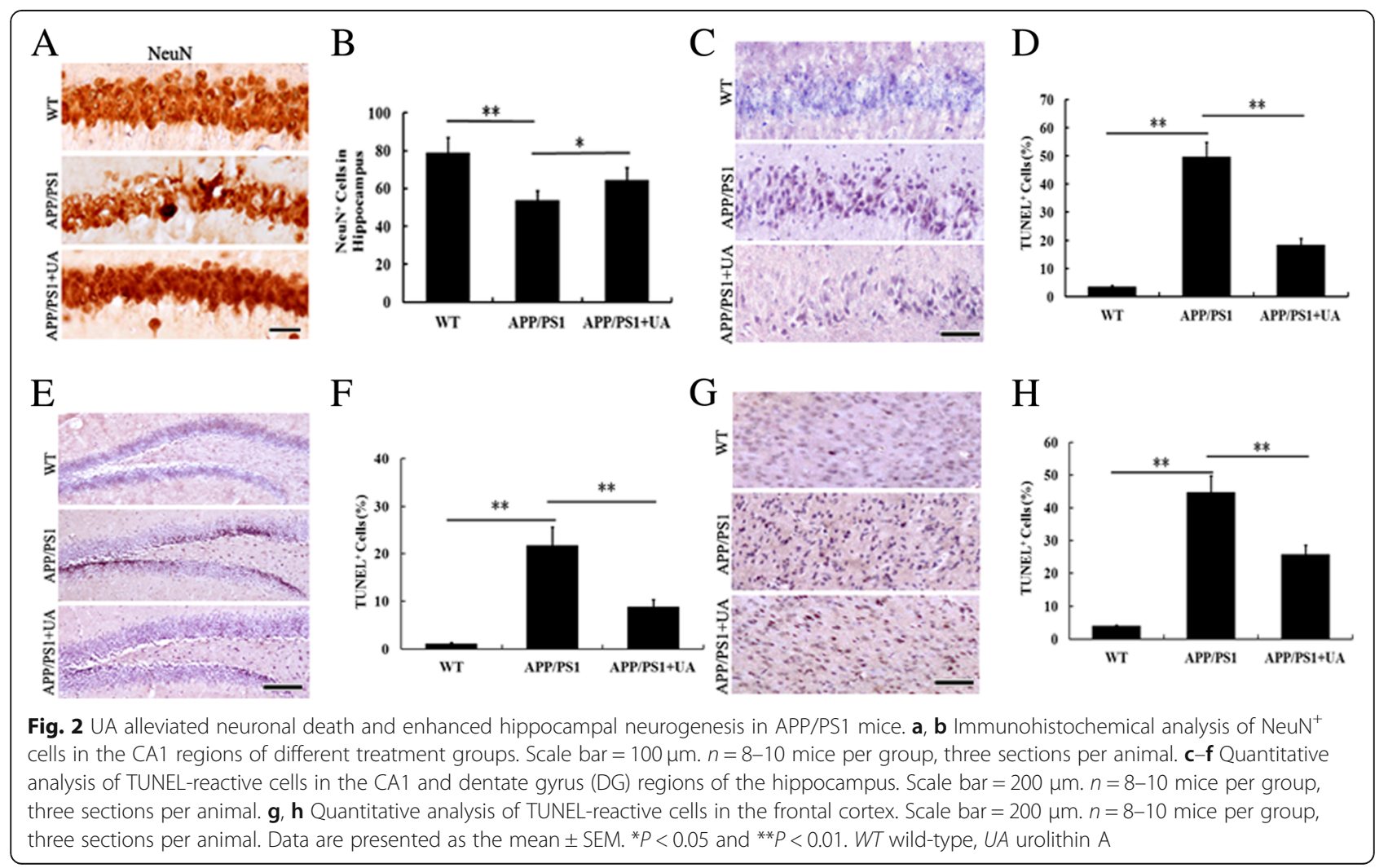




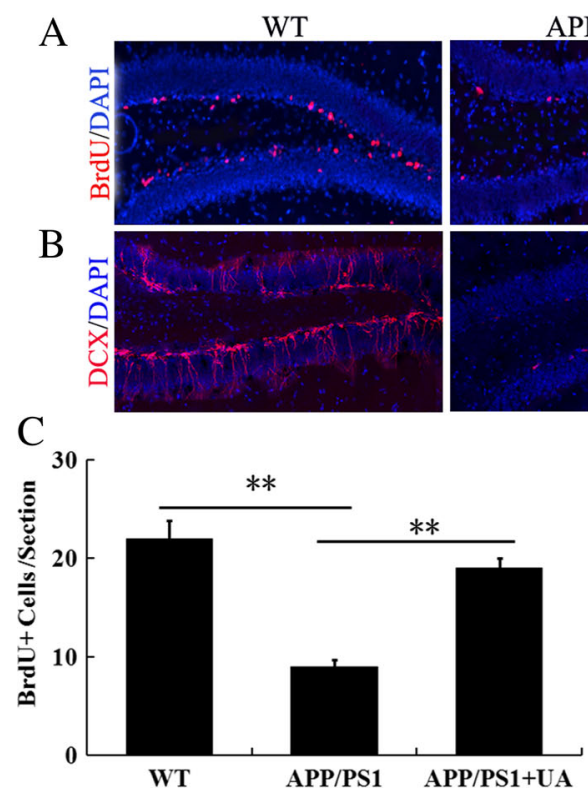

\section{APP/PS1}
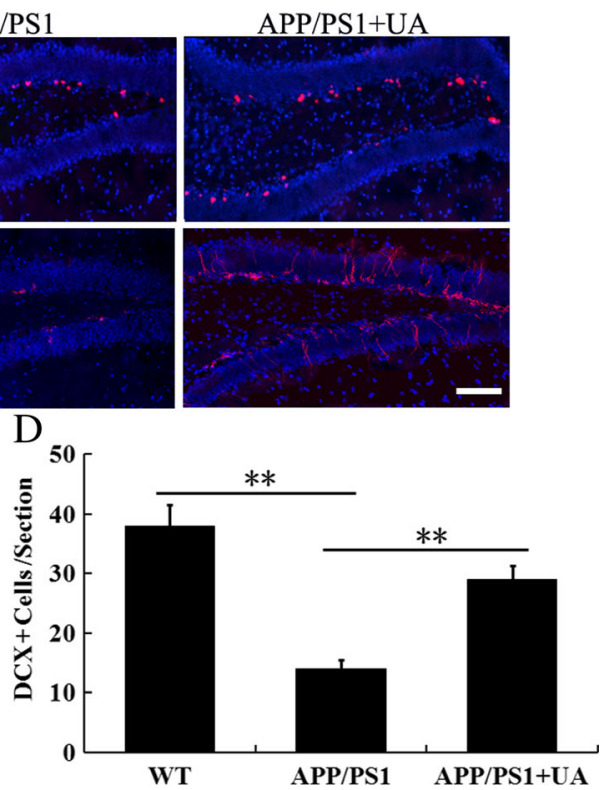

Fig. 3 UA-enhanced hippocampal neurogenesis in APP/PS1 mice. a Representative fields of BrdU-positive cells in the hippocampal dentate gyrus. Scale bar $=200 \mu \mathrm{m}$. b Representative fields of DCX-positive cells in the hippocampal dentate gyrus. Scale bar =200 $\mu \mathrm{m}$. $\mathbf{c}$ BrdU-positive cells in each group. $\mathbf{d}$ Quantification of DCX-positive cells in each group. $n=8-10$ mice per group, three sections per animal. Data are presented as the mean \pm SEM, ${ }^{*} P<0.05$ and ${ }^{*} P<0.01$. WT wild-type, UA urolithin A

(Fig. 4g, h). These results demonstrated that UA decreased $\mathrm{A} \beta$ levels in APP/PS1 mice.

\section{UA attenuates reactive gliosis in APP/PS1 mice}

A typical hallmark of the AD brain is the presence of activated astrocytes and microglia surrounding $A \beta$ plaques, which contributes to the inflammatory process of brain injury [18]. To investigate the anti-inflammatory effects of UA on APP/PS1 mice, we assessed the microglial and astrocytic reactivity in the cortex and hippocampus by staining with antibodies against Iba1 and GFAP, respectively. The staining revealed that reactive astrogliosis and microgliosis were markedly observed in the cortex and hippocampus of APP/PS1 mice compared with WT controls. Moreover, staining for both activated microglia and astrocytes was heavy in the vehicle-treated APP/PS1 mice and significantly less intense in the UA-treated APP/PS1 mice (Fig. $5 \mathrm{a}-\mathrm{d}$ ). We also observed that $\mathrm{A} \beta$ plaques were surrounded by reactive microglia and astrocyte in the brains of vehicle-treated APP/PS1 mice, whereas reactive microglia and astrocytes were reduced around $A \beta$ plaques in the brains of UA-treated APP/PS1 mice (Fig. 5e, f). These results indicated that UA effectively decreased microglia and astrocyte activation in APP/PS1 mice.

UA decreases proinflammatory cytokine levels in APP/PS1 mice

Activated glia stimulated by $A \beta$ has been reported to upregulate the expression of several proinflammatory chemokines and cytokines including IL-1 $\beta$, IL- 6 , and TNF- $\alpha$, which could result in an increase of $A \beta$ production, neuronal death, and cognitive deficits [19]. Thus, we measured the expression of these three cytokines in the different experimental groups. Our results demonstrated that the levels of IL-1 $\beta$, IL- 6 , and TNF- $\alpha$ were markedly increased in the cortex and hippocampus of the APP/PS1 group compared with the WT group (Fig. 6a-c). Interestingly, UA significantly reduced the levels of the inflammatory mediators IL-1 $\beta$ and TNF- $\alpha$ in both the cortex and hippocampus of APP/PS1 animals (Fig. 6a-c), suggesting that UA could inhibit the secretion of inflammatory cytokines. In addition, quantitative polymerase chain reaction (qPCR) results confirmed the above results (Fig. $6 \mathrm{~d}-\mathrm{f}$ ). Taken together, these data indicated that UA effectively decreased the expression of proinflammatory factors released by activated glia.

\section{Multiple proteins participate in the working mechanism of UA in APP/PS1 mice}

Previous studies have shown that $5^{\prime}$-AMP-activated protein kinase (AMPK)/Beta-site APP-cleaving enzyme 1 (Bace1) signaling was responsible for APP processing and $A \beta$ production $[20,21]$. It is well known that the release of proinflammatory factors requires nuclear factor kappa-light-chain-enhancer of activated B cells (NFKB) and/or the activation of the mitogen-activated protein kinase (MAPK) p38. AMPK/NFkB and AMPK/p38MAPK 


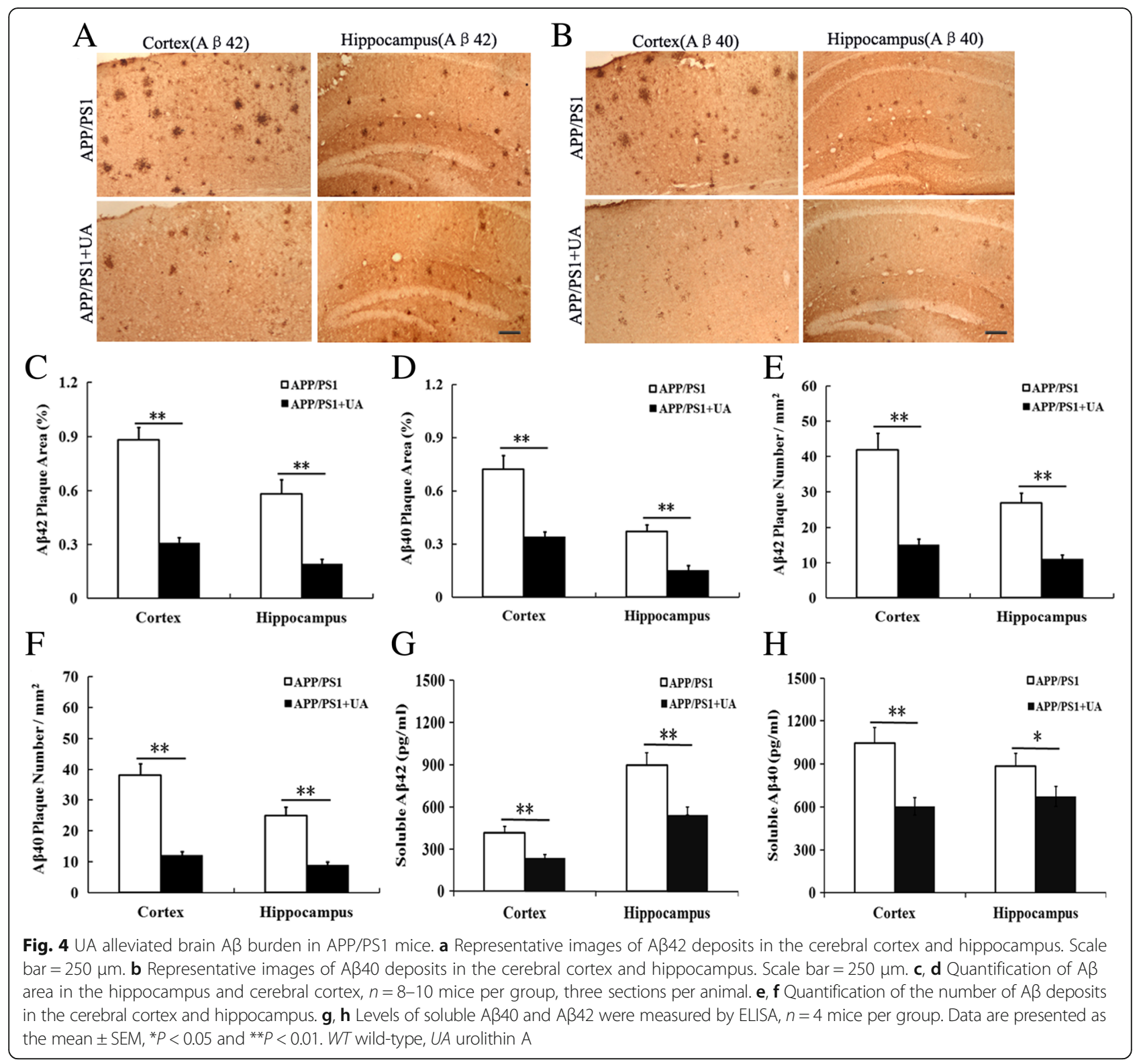

signaling pathways are involved in the decreased neuroinflammatory response $[22,23]$. To further investigate the mechanisms involved in UA-mediated neuroprotection and anti-inflammation, the activation/phosphorylation of AMPK, p65NFkB, p38MAPK, and Bace1, APP proteins were studied. Our results showed that in the cortex and hippocampus of APP/PS1 mice, phosphorylated (p-) AMPK was markedly decreased compared with the WT group (Fig. 7a, b), whereas the levels of p-P65NFKB, p-P38MAPK, and Bace1, APP were notably enhanced compared with the WT group (Fig. 7c-j). Strikingly, after UA treatment, the APP/PS1 mice showed a remarkable increase in the expression of $\mathrm{p}$-AMPK and a significant decrease in the expression of p-P65NFkB, p-P38MAPK, and Bace1, APP (Fig. 7a-j). Our findings indicated that the UA-induced alterations of these critical signaling proteins might contribute to its neuroprotective effect in AD.

\section{Discussion}

$\mathrm{AD}$ is a neurodegenerative disorder characterized by progressive memory deficits and cognitive decline. Our findings in this study demonstrated that APP/PS1 transgenic mice exhibited severe memory loss. Recent reports have indicated that dietary supplementation with pomegranate extract $(\mathrm{PE})$, which is ultimately metabolized by gut microflora to yield UA, ameliorated the loss of synaptic-structure proteins and improved behavioral performance in APPsw/Tg 2576 mice [24, 25] and APP/PS1 mice [26]. In contrast, another study reported that PE did not improve the cognitive performance of transgenic 

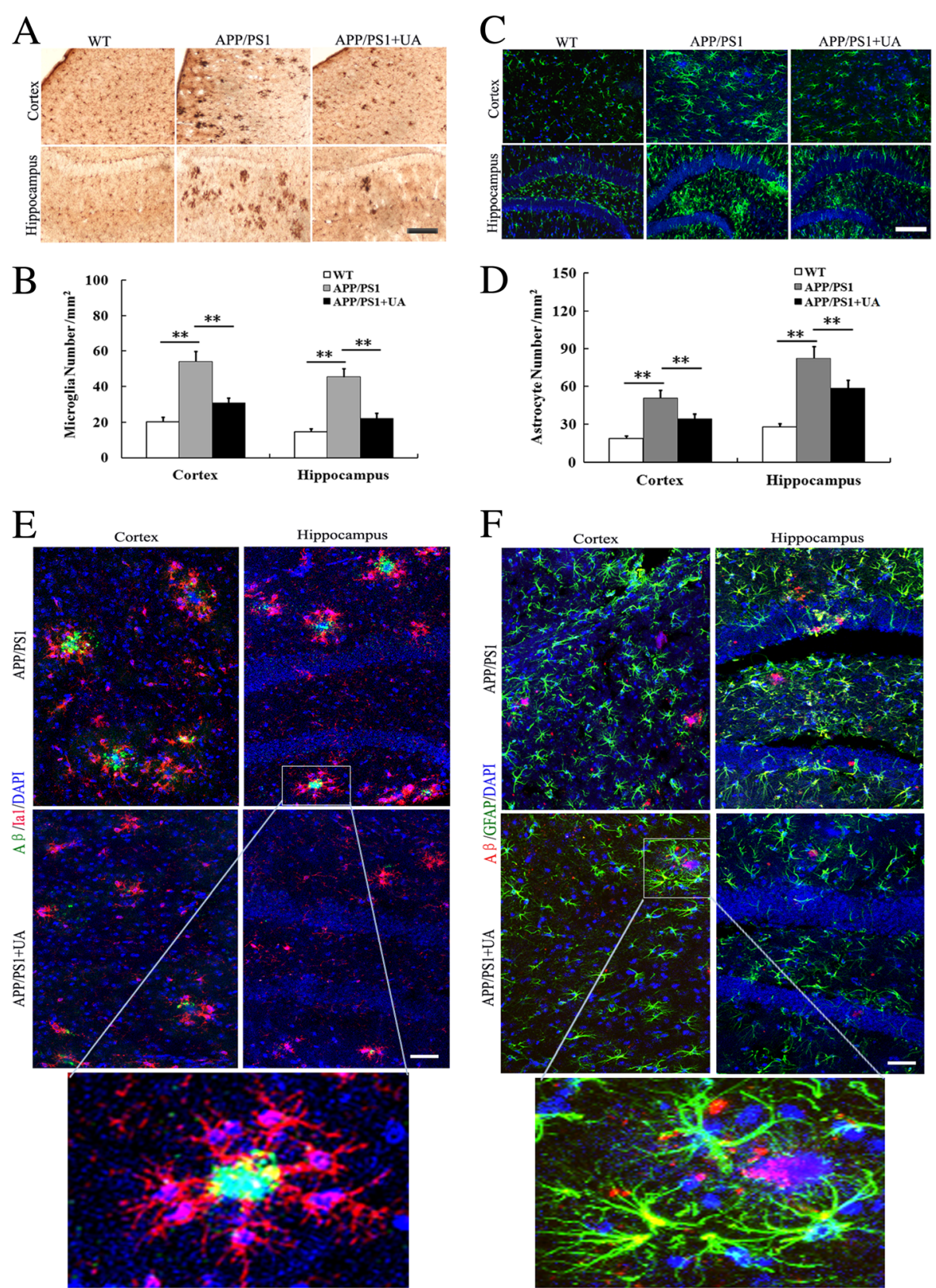

Fig. 5 UA decreased glial reactivity in APP/PS1 mice. a Representative immunostaining of Iba-1 in the cerebral cortex and hippocampus of the different groups. Scale bar $=200 \mu \mathrm{m}$. b Quantification of microglia number in the cortex and hippocampus. c Colocalization of fluorescent GFAP (green) and DAPI (blue) in the hippocampus and cortex. Scale bar $=200 \mu \mathrm{m}$. d Quantification of astrocyte number in the cerebral cortex and hippocampus. e Colocalization of fluorescent A $\beta$ (green), Iba1 (red), and DAPI (blue) in the cerebral cortex and hippocampus. Scale bar= $50 \mu \mathrm{m}$. $\mathbf{f}$ Colocalization of fluorescent A $\beta$ (red), GFAP (green), and DAPI (blue) in the cerebral cortex and hippocampus. Scale bar $=50 \mu \mathrm{m}$. All of the quantified data are presented as the mean \pm SEM,$n=8-10$ /group, three sections per animal, ${ }^{* *} P<0.01$. WT wild-type, UA urolithin $A$

AD mice [27]. We speculated that the contradictory effects of PE may be attributed to its poor absorption, different active ingredients, and functional concentrations in vivo. In this study, APP/PS1 mice were intragastrically administered with UA. We found that UA treatment significantly ameliorated cognitive impairment. Our study also elucidated some mechanisms underlying the beneficial effects of UA in AD.
The brain in AD shows a selective and progressive degeneration of neurons, which can contribute to cognitive impairment [28]. Previous study has shown marked neuronal loss in both the CA1 field and dentate gyrus (DG) in APP/PS1 mice at 16 months of age [29]. No neuron loss was found in the neocortex of aged APPPS1 mice but a significant $11 \%$ neuron loss was found in the 

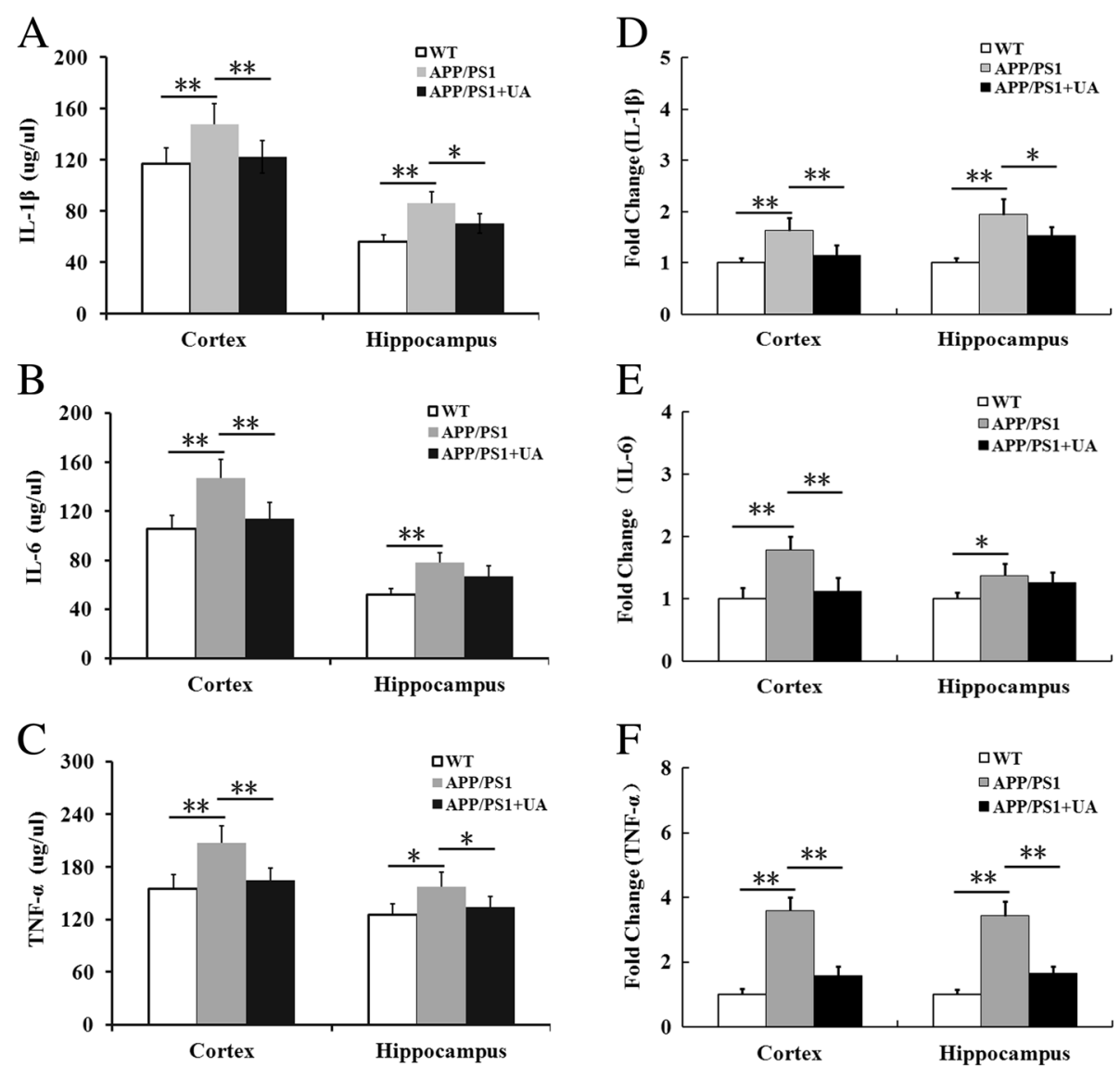

Fig. 6 UA reduced proinflammatory cytokine production in APP/PS1 Mice. a-c $I L-1 \beta, I L-6$, and TNF-a levels in the cortex and hippocampus were measured by ELISA. $\mathbf{d}-\mathbf{f}$ The expressions of IL-1 $\beta, I L-6$, and TNF-a mRNA in the cortex and hippocampus were detected by quantitative RT-PCR. Data are presented as the mean $\pm \mathrm{SEM}, n=4,{ }^{*} P<0.05$ and ${ }^{* *} P<0.01$. WT wild-type, UA urolithin A

dentate gyrus of 17-month-old APPPS1 mice compared with age-matched control mice [30]. However, neuron loss is also reported for the hippocampal CA1 and frontal cortex but did not reach statistical significance in 12-month-old APP/PS1 mouse [31]. Amazingly, study shows that neuron death has been significantly enhanced in the cortex and hippocampus of 3-month-old male APP/PS1 mice compared with age-matched control mice [32]. In the current study, we found that 30-week-old APP/PS1 mice had substantial neuronal loss in the hippocampal CA1. Studies have confirmed that neuronal apoptosis is observed both in APP/PS1 mice [18] and $\mathrm{AD}$ patients [33]. Inhibiting hippocampal neuronal apoptosis relieved the cognitive dysfunction [34]. In our study, we found that UA significantly increased the number of NeuN-positive neurons and suppressed the apoptosis of hippocampal cells in APP/PS1 mice. These results indicated that UA not only repaired damaged neurons but also prevented hippocampal neuronal loss in APP/PS1 mice. Impaired hippocampal neurogenesis is involved in cognitive dysfunction. Some natural nuts and berries, when metabolized into UA, were shown to enhance mammalian hippocampal neurogenesis and improve cognition [35, 36]. Accordingly, we observed decreased neurogenesis in the hippocampus of APP/PS1 mice. Importantly, UA treatment of APP/PS1 mice significantly increased hippocampal neurogenesis, which might explain the improvement of learning and memory we observed in UA-treated transgenic animals.

Excessive $A \beta$ aggregation into plaques is widely considered as one of the first changes that occur in the brain of AD [37]. Recent reports have shown that dietary supplementation with PE delayed the formation of senile plaques by decreasing the brain content of $A \beta 1-40$ and A $\beta 1-42$ [24, 26]. However, a different study showed that urolithins, but not PE or its predominant ellagitannins, prevented $\beta$-amyloid fibrillation in vitro [38]. In our study, we observed a marked increase of $A \beta$ levels in the brains of APP/PS1 mice. Notably, UA treatment reduced $\mathrm{A} \beta$ deposits in the cortex and hippocampus of APP/PS1 mice, suggesting that UA inhibited the accumulation of $\mathrm{A} \beta$ deposits in APP/PS1 mice.

Previous studies have shown that neuroinflammation increased $A \beta$ production, and that aggregated $A \beta$ 


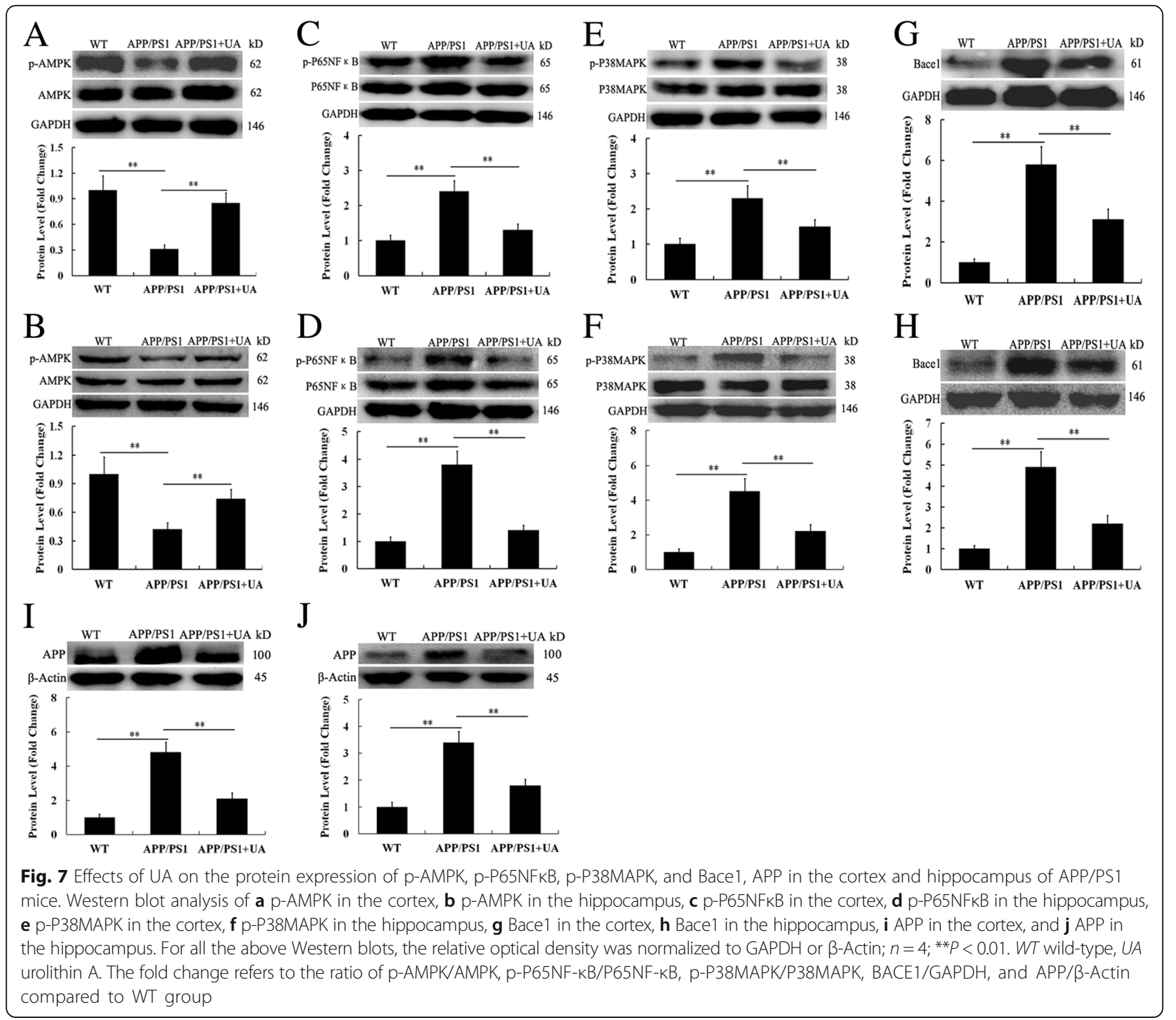

triggered microgliosis and astrogliosis, resulting in a proinflammatory state [39]. In our study, UA not only decreased the levels of activated microglia and astrocytes, but it also reduced $\mathrm{A} \beta$ levels in $\mathrm{AD}$ mice. It has been reported that urolithins possessed anti-inflammatory and antioxidative properties, with urolithin A exhibiting the strongest anti-inflammatory activity $[10,12,40]$. Therefore, we hypothesized that UA might suppress neuroinflammation and lead to the decrease of $A \beta$ production. Accordingly, we found that UA treatment reduced the production of inflammatory cytokines in APP/PS1 mice, which suggested that UA may also affect glia. Previous evidence has demonstrated the infiltration of activated glia around $\mathrm{A} \beta$ plaques in $\mathrm{AD}$ brains [41], indicating that glia may provide the initial neuroprotective effect in $\mathrm{AD}$ pathology by phagocytosing $A \beta$. Consistent with the observations above, our results showed that UA might attenuate the $\mathrm{A} \beta$ burden in APP/PS1 mice by promoting glial phagocytosis (Fig. 5e, f).

The UA-mediated inhibition of neuroinflammation and neuronal apoptosis may contribute to the improvement of $\mathrm{AD}$ pathophysiology. However, the underlying molecular mechanisms are still largely unclear. Previous studies reported that PE activated AMPK in the hypothalamus [42], the liver, and adipose tissue [43]. Phosphorylated AMPK activated Nrf2, which promoted the expression of antioxidant proteins that protect against the oxidative damage triggered by inflammation [44]. In vitro data showed that UA attenuated triglyceride accumulation via AMPK activation in adipocytes as well as hepatocytes [45]. However, few studies have investigated whether AMPK is activated by urolithins in vivo. Our data addressed the question of the potential activation of AMPK by urolithins in vivo by showing that UA 
dramatically enhanced cortical and hippocampal AMPK activation in APP/PS1 mice.

Previous evidence also suggested that AMPK activation decreased $A \beta$ production and could present a new potential therapeutic strategy in AD [46]. Activated AMPK has been reported to regulate the expression and trafficking of Bace1 in APP processing and A $\beta$ generation [21]. Furthermore, AMPK activation increased autophagy signaling and facilitated lysosomal degradation of $A \beta$ [47]. In our study, we found that the levels of Bace1 were reduced by UA treatment in APP/PS1 mice, indicating that AMPK/ Bace1 signaling may be involved in the UA-induced decrease in A $\beta$ deposition by reducing the cleavage of APP.

Activation and nuclear translocation of $\mathrm{NFKB}$ have been shown to elicit the release of proinflammatory cytokines, whereas inhibiting $\mathrm{AMPK} / \mathrm{NFKB}$ signaling reduced the production of proinflammatory cytokines [22]. A large body of evidence has demonstrated that AMPK activation repressed $\mathrm{NF}_{\kappa} \mathrm{B}$ signaling by activating SIRT1 [48], stimulating FOXO proteins [49], and suppressing ER stress [50]. Recent studies suggested that UA inhibited the phosphorylation and nuclear translocation of the $N F \kappa B$ p65 subunit, which reduced the expression of proinflammatory genes and diminished nitric oxide production [51, 52]. Consistent with this finding, we observed an obvious enhancement of $\mathrm{NFKB}$ phosphorylation in APP/PS1 mice, indicating that $A \beta$ activated NFKB. More importantly, UA attenuated the levels of $\mathrm{p}-\mathrm{P} 65 \mathrm{NFK} \mathrm{B}$, which explains the anti-inflammatory effects of UA in APP/PS1 mice. In addition, P38MAPK has also been shown to regulate proinflammatory signaling networks and the biosynthesis of cytokines including TNF- $\alpha$ and IL-1 $\beta$ [53]. Studies have demonstrated that the activation of P38MAPK by A $\beta$ occurred in the postmortem brains of $\mathrm{AD}$ patients and animal models, indicating that p38MAPK is involved in the pathogenesis of AD [54]. Inhibition of P38MAPK effectively alleviated the inflammatory response, $A \beta$ deposits, and cognitive impairment in brains with $\mathrm{AD}[55,56]$. Thus, P38MAPK inhibitors are considered promising drug candidates for the treatment of $\mathrm{AD}$. Whether the inflammation in $\mathrm{AD}$ is primarily induced through P38MAPK signaling remains unclear and requires further study. Many studies have provided evidence that UA decreased the phosphorylation levels of P38MAPK in LPS-stimulated microglia and IL-1 $\beta$-treated human colonic fibroblasts [14]. However, another study revealed that UA increased the mRNA and protein expression of P38MAPK in HepG2 cells and bladder cancer cells $[57,58]$. Our study found that activated P38MAPK was affected by UA treatment, with significant decreases in the levels of p-P38 observed in the brains of UA-treated APP/PS1 mice. Taken together, these findings suggest that suppression of $\mathrm{P} 65 \mathrm{NFKB}$ and P38MAPK activity may contribute to the anti-inflammatory effect of UA.

\section{Conclusion}

In summary, our results in an AD mouse model demonstrated the protective effects of UA on AD pathology by its targeting of multiple pathological processes such as reactive gliosis, inflammatory signaling, $\mathrm{AB}$ plaque formation, and apoptosis. Our findings indicate that UA may serve as a promising therapeutic agent for $\mathrm{AD}$.

\section{Abbreviations}

AD: Alzheimer's disease; AMPK: 5'-AMP-activated protein kinase; A $\beta$ : Amyloid$\beta$; BrdU: 5-Bromo-2'-deoxyuridine; DAPI: 4',6-Diamidino-2-phenylindole; DCX: Doublecortin; EA: Ellagic acid; ELISA: Enzyme-linked immunosorbent assay; ETs: Ellagitannins; MAPK: Mitogen-activated protein kinase; NeuN: Neuronal nuclei; NFkB: Nuclear factor-kappa B; PE: Pomegranate extract; TUNEL: Terminal deoxynucleotidyl transferase dUTP nick end labeling; UA: Urolithin A; WT: Wild-type

\section{Acknowledgements}

Not applicable.

\section{Funding}

This work was supported by the National Natural Science Foundation of China (81371217), the Natural Science Foundation of Guangdong (2017A030313520), Science and Technology Foundation of Guangdong Province (2016A020214019), Science and Technology Foundation of Guangzhou (201707010231), and Science Foundation of Education Bureau of Guangzhou City (1201610239).

\section{Availability of data and materials}

All data supporting the conclusions of this study are presented in the manuscript.

\section{Authors' contributions}

$A G X$ and $D H L$ conceived and designed the project. ZG, JYH, BX, ZRO, LZ, $X H L, X J Y$, and XJK performed the experiments. AGX, XDS, XSH, and LPX supervised the project. AGX, QQL, and ZG analyzed the data and wrote the paper. All authors read and approved the final manuscript.

Ethics approval and consent to participate

All animal studies were performed with the approval by the Ethics Committee of Guangzhou Medical University, Guangdong, China.

Consent for publication

Not applicable.

Competing interests

The authors declare that they have no competing interests.

\section{Publisher's Note}

Springer Nature remains neutral with regard to jurisdictional claims in published maps and institutional affiliations.

\section{Author details}

${ }^{1}$ Institute of Neuroscience and Department of Neurology of the Second Affiliated Hospital of Guangzhou Medical University, Key Laboratory of Neurogenetics and Channelopathies of Guangdong Province and the Ministry of Education of China, Guangzhou 510260, China. ²Department of Neurology of the Sixth Affiliated Hospital, Guangzhou Medical University, Guangzhou 511518, China.

Received: 26 November 2018 Accepted: 5 March 2019

Published online: 14 March 2019

\section{References}

1. Katsouri L, Lim YM, Blondrath K, Eleftheriadou I, Lombardero L, Birch AM, Mirzaei N, Irvine EE, Mazarakis ND, Sastre M. PPARY-coactivator-1a gene transfer reduces neuronal loss and amyloid- $\beta$ generation by reducing $\beta$ secretase in an Alzheimer's disease model. Proc Natl Acad Sci U S A. 2016; 113:12292-7. 
2. Gold M, El Khoury J. $\beta$-amyloid, microglia, and the inflammasome in Alzheimer's disease. Semin Immunopathol. 2015;37:607-11.

3. Hanzel CE, Pichet-Binette A, Pimentel LS, lulita MF, Allard S, Ducatenzeiler A, Do Carmo S, Cuello AC. Neuronal driven pre-plaque inflammation in a transgenic rat model of Alzheimer's disease. Neurobiol Aging. 2014;35:2249-62.

4. Hoeijmakers L, Ruigrok SR, Amelianchik A, Ivan D, van Dam AM, Lucassen PJ, Korosi A. Early-life stress lastingly alters the neuroinflammatory response to amyloid pathology in an Alzheimer's disease mouse model. Brain Behav Immun. 2017:63:160-75.

5. Ries M, Sastre M. Mechanisms of A $\beta$ clearance and degradation by glial cells. Front Aging Neurosci. 2016;8:160.

6. in $t^{\prime}$ Veld BA, Ruitenberg A, Hofman A, Launer $L$, van Duijn CM, Stijnen T, Breteler MM, Stricker BH. Nonsteroidal antiinflammatory drugs and the risk of Alzheimer's disease. N Engl J Med. 2001;345:1515-21.

7. Stewart WF, Kawas C, Corrada M, Metter EJ. Risk of Alzheimer's disease and duration of NSAID use. Neurology. 1997;48:626-32.

8. Larrosa M, González-Sarrías A, García-Conesa MT, Tomás-Barberán FA, Espín JC. Urolithins, ellagic acid-derived metabolites produced by human colonic microflora, exhibit estrogenic and antiestrogenic activities. J Agric Food Chem. 2006;54:1611-20.

9. Tomás-Barberán FA, García-Villalba R, González-Sarrías A, Selma MV, Espín JC. Ellagic acid metabolism by human gut microbiota: consistent observation of three urolithin phenotypes in intervention trials, independent of food source, age, and health status. J Agric Food Chem. 2014;62:6535-8.

10. Larrosa M, González-Sarrías A, Yáñez-Gascón MJ, Selma MV, Azorín-Ortuño M, Toti S, Tomás-Barberán F, Dolara P, Espín JC. Anti-inflammatory properties of a pomegranate extract and its metabolite urolithin-A in a colitis rat model and the effect of colon inflammation on phenolic metabolism. J Nutr Biochem. 2010;21:717-25.

11. Ishimoto $H$, Shibata $M$, Myojin $Y$, Ito $H$, Sugimoto $Y$, Tai A, Hatano T. In vivo anti-inflammatory and antioxidant properties of ellagitannin metabolite urolithin A. Bioorg Med Chem Lett. 2011;21(19):5901-4.

12. Giménez-Bastida JA, González-Sarrías A, Larrosa M, Tomás-Barberán F, Espín JC, García-Conesa MT. Ellagitannin metabolites, urolithin A glucuronide and its aglycone urolithin A, ameliorate TNF-a-induced inflammation and associated molecular markers in human aortic endothelial cells. Mol Nutr Food Res. 2012;56:784-96.

13. Giménez-Bastida JA, Larrosa M, González-Sarrías A, Tomás-Barberán F, Espín JC, García-Conesa MT. Intestinal ellagitannin metabolites ameliorate cytokineinduced inflammation and associated molecular markers in human colon fibroblasts. J Agric Food Chem. 2012;60:8866-76.

14. González-Sarrías A, Larrosa M, Tomás-Barberán FA, Dolara P, Espín JC. NFkappaB-dependent anti-inflammatory activity of urolithins, gut microbiota ellagic acid-derived metabolites, in human colonic fibroblasts. Br J Nutr. 2010;104:503-12.

15. West MJ, Coleman PD, Flood DG, Troncoso JC. Differences in the pattern of hippocampal neuronal loss in normal ageing and Alzheimer's disease. Lancet. 1994;344:769-72.

16. Raefsky SM, Furman R, Milne G, Pollock E, Axelsen P, Mattson MP. Shchepinov MS. Deuterated polyunsaturated fatty acids reduce brain lipid peroxidation and hippocampal amyloid $\beta$-peptide levels, without discernable behavioral effects in an APP/PS1 mutant transgenic mouse model of Alzheimer's disease. Neurobiol Aging. 2018;66:165-76.

17. Shors TJ, Miesegaes G, Beylin A, Zhao M, Rydel T, Gould E. Neurogenesis in the adult is involved in the formation of trace memories. Nature. 2001;410:372-6.

18. Ou Z, Kong X, Sun X, He X, Zhang L, Gong Z, Huang J, Xu B, Long D, Li J, et al. Metformin treatment prevents amyloid plaque deposition and memory impairment in APP/PS1 mice. Brain Behav Immun. 2018;69:351-63.

19. Fu AK, Hung KW, Yuen MY, Zhou X, Mak DS, Chan IC, Cheung TH, Zhang B, Fu WY, Liew FY, et al. IL-33 ameliorates Alzheimer's disease-like pathology and cognitive decline. Proc Natl Acad Sci U S A. 2016;113:E2705-13.

20. Li S, Hou H, Mori T, Sawmiller D, Smith A, Tian J, Giunta B, Sanberg PR, Zhang $\mathrm{S}$, et al. Swedish mutant APP-based BACE1 binding site peptide reduces APP $\beta$-cleavage and cerebral AB levels in Alzheimer's mice. Sci Rep. 2015;5:11322.

21. Chen Y, Zhou K, Wang R, Liu Y, Kwak YD, Ma T, Thompson RC, Zhao Y, Smith L, Gasparini L, et al. Antidiabetic drug metformin (GlucophageR) increases biogenesis of Alzheimer's amyloid peptides via up-regulating BACE1 transcription. Proc Natl Acad Sci U S A. 2009;106:3907-12.

22. Li W, Qiu X, Jiang H, Zhi Y, Fu J, Liu J. Ulinastatin inhibits the inflammation of LPS-induced acute lung injury in mice via regulation of AMPK/NF-KB pathway. Int Immunopharmacol. 2015;29:560-7.
23. Chen S, Zhao L, Sherchan P, Ding Y, Yu J, Nowrangi D, Tang J, Xia Y, Zhang $\mathrm{JH}$. Activation of melanocortin receptor 4 with RO27-3225 attenuates neuroinflammation through AMPKJJNK/P38 MAPK pathway after intracerebral hemorrhage in mice. J Neuroinflammation. 2018;15:106.

24. Hartman RE, Shah A, Fagan AM, Schwetye KE, Parsadanian M, Schulman RN, Finn MB, Holtzman DM. Pomegranate juice decreases amyloid load and improves behavior in a mouse model of Alzheimer's disease. Neurobiol Dis. 2006;24:506-15.

25. Subash S, Braidy N, Essa MM, Zayana AB, Ragini V, Al-Adawi S, Al-Asmi A, Guillemin GJ. Long-term (15 mo) dietary supplementation with pomegranates from Oman attenuates cognitive and behavioral deficits in a transgenic mice model of Alzheimer's disease. Nutrition. 2015;31:223-9.

26. Rojanathammanee L, Puig KL, Combs CK. Pomegranate polyphenols and extract inhibit nuclear factor of activated T-cell activity and microglial activation in vitro and in a transgenic mouse model of Alzheimer disease. J Nutr. 2013;143:597-605.

27. Ahmed AH, Subaiea GM, Eid A, Li L, Seeram NP, Zawia NH. Pomegranate extract modulates processing of amyloid- $\beta$ precursor protein in an aged Alzheimer's disease animal model. Curr Alzheimer Res. 2014;11:834-43.

28. Drapeau E, Nora Abrous D. Stem cell review series: role of neurogenesis in age-related memory disorders. Aging Cell. 2008;7:569-89.

29. Chao F, Jiang L, Zhang Y, Zhou C, Zhang L, Tang J, Liang X, Qi Y, Zhu Y, Ma $J$, et al. Stereological investigation of the effects of treadmill running exercise on the hippocampal neurons in middle-aged APP/PS1 transgenic mice. J Alzheimers Dis. 2018;63:689-703.

30. Rupp NJ, Wegenast-Braun BM, Radde R, Calhoun ME, Jucker M. Early onset amyloid lesions lead to severe neuritic abnormalities and local, but not global neuron loss in APPPS1 transgenic mice. Neurobiol Aging. 2011;32:2324.

31. Takeuchi A, Irizarry MC, Duff $K$, Saido TC, Hsiao Ashe K, Hasegawa M, Mann DM, Hyman BT, Iwatsubo T. Age-related amyloid beta deposition in transgenic mice overexpressing both Alzheimer mutant presenilin 1 and amyloid beta precursor protein Swedish mutant is not associated with global neuronal loss. Am J Pathol. 2000;157(1):331-9.

32. Long Z, Zheng M, Zhao L, Xie P, Song C, Chu Y, Song W, He G. Valproic acid attenuates neuronal loss in the brain of APP/PS1 double transgenic Alzheimer's disease mice model. Curr Alzheimer Res. 2013;10(3):261-9.

33. Stygelbout V, Leroy K, Pouillon V, Ando K, D'Amico E, Jia Y, Luo HR, Duyckaerts C, Erneux C, Schurmans S, et al. Inositol trisphosphate 3-kinase B is increased in human Alzheimer brain and exacerbates mouse Alzheimer pathology. Brain. 2014;137:537-52.

34. Puzzo D, Loreto C, Giunta S, Musumeci G, Frasca G, Podda MV, Arancio O, Palmeri A. Effect of phosphodiesterase- 5 inhibition on apoptosis and beta amyloid load in aged mice. Neurobiol Aging. 2014;35:520-31.

35. Gorji N, Moeini R, Memariani Z. Almond, hazelnut and walnut, three nuts for neuroprotection in Alzheimer's disease: a neuropharmacological review of their bioactive constituents. Pharmacol Res. 2018;129:115-27.

36. Shukitt-Hale B, Bielinski DF, Lau FC, Willis LM, Carey AN, Joseph JA. The beneficial effects of berries on cognition, motor behaviour and neuronal function in ageing. Br J Nutr. 2015;114:1542-9.

37. Holtzman DM, Morris JC, Goate AM. Alzheimer's disease: the challenge of the second century. Sci Transl Med. 2011;3:77sr1.

38. Yuan T, Ma H, Liu W, Niesen DB, Shah N, Crews R, Rose KN, Vattem DA, Seeram NP. Pomegranate's neuroprotective effects against Alzheimer's disease are mediated by urolithins, its ellagitannin-gut microbial derived metabolites. ACS Chem Neurosci. 2016;7:26-33.

39. Walker D, Lue LF. Anti-inflammatory and immune therapy for Alzheimer's disease: current status and future directions. Curr Neuropharmacol. 2007;5: 232-43.

40. Piwowarski JP, Kiss AK, Granica S, Moeslinger T. Urolithins, gut microbiotaderived metabolites of ellagitannins, inhibit LPS-induced inflammation in RAW 264.7 murine macrophages. Mol Nutr Food Res. 2015;59:2168-77.

41. Itagaki S, McGeer PL, Akiyama H, Zhu S, Selkoe D. Relationship of microglia and astrocytes to amyloid deposits of Alzheimer disease. J Neuroimmunol. 1989:24:173-82.

42. Sun W, Yan C, Frost B, Wang X, Hou C, Zeng M, Gao H, Kang Y, Liu J. Pomegranate extract decreases oxidative stress and alleviates mitochondrial impairment by activating AMPK-Nrf2 in hypothalamic paraventricular nucleus of spontaneously hypertensive rats. Sci Rep. 2016;6:34246.

43. Ok E, Do GM, Lim Y, Park JE, Park YJ, Kwon O. Pomegranate vinegar attenuates adiposity in obese rats through coordinated control of AMPK signaling in the liver and adipose tissue. Lipids Health Dis. 2013;12:163. 
44. Mo C, Wang L, Zhang J, Numazawa S, Tang H, Tang X, Han X, Li J, Yang M, Wang $Z$, et al. The crosstalk between Nrf2 and AMPK signal pathways is important for the anti-inflammatory effect of berberine in LPS-stimulated macrophages and endotoxin-shocked mice. Antioxid Redox Signal. 2014;20:574-88.

45. Kang I, Kim Y, Tomás-Barberán FA, Espín JC, Chung S. Urolithin A, C, and D, but not iso-urolithin $A$ and urolithin $B$, attenuate triglyceride accumulation in human cultures of adipocytes and hepatocytes. Mol Nutr Food Res. 2016; 60:1129-38.

46. Vingtdeux V, Giliberto L, Zhao H, Chandakkar P, Wu Q, Simon JE, Janle EM, Lobo J, Ferruzzi MG, Davies P, et al. AMP-activated protein kinase signaling activation by resveratrol modulates amyloid-beta peptide metabolism. J Biol Chem. 2010;285:9100-13.

47. Pei JJ, Hugon J. mTOR-dependent signalling in Alzheimer's disease. J Cell Mol Med. 2008;12:2525-32.

48. Zhang J, Zhang Y, Xiao F, Liu Y, Wang J, Gao H, Rong S, Yao Y, Li J, Xu G. The peroxisome proliferator-activated receptor $\gamma$ agonist pioglitazone prevents NF-kB activation in cisplatin nephrotoxicity through the reduction of p65 acetylation via the AMPK-SIRT1/p300 pathway. Biochem Pharmacol. 2016;101:100-11.

49. Kauppinen A, Suuronen T, Ojala J, Kaarniranta K, Salminen A. Antagonistic crosstalk between NF-KB and SIRT1 in the regulation of inflammation and metabolic disorders. Cell Signal. 2013;25:1939-48.

50. Salvadó L, Coll T, Gómez-Foix AM, Salmerón E, Barroso E, Palomer $X_{\text {, }}$ Vázquez-Carrera M. Oleate prevents saturated-fatty-acid-induced ER stress, inflammation and insulin resistance in skeletal muscle cells through an AMPK-dependent mechanism. Diabetologia. 2013:56:1372-82.

51. Boakye YD, Groyer L, Heiss EH. An increased autophagic flux contributes to the anti-inflammatory potential of urolithin A in macrophages. Biochim Biophys Acta. 1862;2018:61-70.

52. Xu J, Yuan C, Wang G, Luo J, Ma H, Xu L, Mu Y, Li Y, Seeram NP, Huang X, et al. Urolithins attenuate LPS-induced neuroinflammation in BV2Microglia via MAPK, Akt, and NF-KB signaling pathways. J Agric Food Chem. 2018;66:571-80.

53. Munoz L, Ammit AJ. Targeting p38 MAPK pathway for the treatment of Alzheimer's disease. Neuropharmacology. 2010;58:561-8.

54. Pei JJ, Braak E, Braak H, Grundke-labal I, labal K, Winblad B, Cowburn RF. Localization of active forms of C-jun kinase (JNK) and p38 kinase in Alzheimer's disease brains at different stages of neurofibrillary degeneration. J Alzheimers Dis. 2001;3:1-48.

55. Sabogal-Guáqueta AM, Osorio E, Cardona-Gómez GP. Linalool reverses neuropathological and behavioral impairments in old triple transgenic Alzheimer's mice. Neuropharmacology. 2016;102:111-20.

56. Kim TI, Lee YK, Park SG, Choi IS, Ban JO, Park HK, Nam SY, Yun YW, Han SB, Oh KW, et al. I-Theanine, an amino acid in green tea, attenuates betaamyloid-induced cognitive dysfunction and neurotoxicity: reduction in oxidative damage and inactivation of ERK/p38 kinase and NF-kappaB pathways. Free Radic Biol Med. 2009;47:1601-10.

57. Wang Y, Qiu Z, Zhou B, Liu C, Ruan J, Yan Q, Liao J, Zhu F. In vitro antiproliferative and antioxidant effects of urolithin $\mathrm{A}$, the colonic metabolite of ellagic acid, on hepatocellular carcinomas HepG2 cells. Toxicol in Vitro. 2015:29:1107-15.

58. Qiu Z, Zhou B, Jin L, Yu H, Liu L, Liu Y, Qin C, Xie S, Zhu F. In vitro antioxidant and antiproliferative effects of ellagic acid and its colonic metabolite, urolithins, on human bladder cancer T24 cells. Food Chem Toxicol. 2013;59:428-37.

Ready to submit your research? Choose BMC and benefit from:

- fast, convenient online submission

- thorough peer review by experienced researchers in your field

- rapid publication on acceptance

- support for research data, including large and complex data types

- gold Open Access which fosters wider collaboration and increased citations

- maximum visibility for your research: over $100 \mathrm{M}$ website views per year

At BMC, research is always in progress.

Learn more biomedcentral.com/submissions 